\title{
PENGALAMAN KELUARGA MENGHADAPI HOSPITALISASI PASIEN KRITIS DI RUANG ICU RS Dr. BRATANATA JAMBI
}

\author{
Mega Herawati ${ }^{1}$, Fithriyani $^{2}$ \\ ${ }^{1,2}$ Program Studi S1Keperawatan STIKes Baiturahim Jambi \\ Email:Megaherawati20@yahoo.co.id
}

\begin{abstract}
Hospitalization is a process that for a reason of planning or emergency, which requires patients to stay in the hospital. Hospital patient care not only causes problems for the patient, but also for the family. The purpose of this study was to determine the family's experience in dealing with hospitalization of critical patients in ICU Dr. Bratanata Hospital Jambi. This research is a qualitative research with phenomenology approach using Colaizzi model analysis which is implemented in Dr. Bratanata Hospital Jambi. Participants in this study were 5 participants with core family inclusion criteria who had been waiting for more than 7 days and were over 18 years old. Data collection techniques with in-depth interviews.The results of the study there is a Critical Hospitalization Patient Response in the ICU room for the family consisting of physical response include fatigue, body complaints and sleep disorders; Psychological responses include anxiety, tension, fear and sadness; Social responses include reduced communication and new experiences.
\end{abstract}

Keywords: Hospitalization, family, critical patients

\begin{abstract}
ABSTRAK
Hospitalisasi merupakan suatu proses yang karena suatu alasan berencana atau darurat, dimana mengharuskan pasien untuk tinggal di Rumah Sakit. Perawatan pasien di Rumah Sakit tidak hanya menimbulkan masalah bagi pasien, tetapi juga bagi keluarga. Tujuan penelitian ini adalah untuk menggali lebih dalam pengalaman keluarga menghadapi hospitalisasi pasien kritis di ruang ICU RS Dr. Bratanata Jambi. Penelitian ini adalah penelitian kualitatif dengan pendekatan fenomenologi menggunakan analisis model Colaizzi yang dilaksanakan di RS Dr. Bratanata Jambi. Partisipan pada penelitian ini berjumlah 5 partisipan dengan kriteria inklusi keluarga inti yang sudah menunggu lebih dari 7 hari dan berusia lebih dari 18 tahun. Teknik pengumpulan data dengan wawancara mendalam. Hasil penelitian terdapat tema Respon Hospitalisasi Pasien Kritis di Ruang ICU bagi Keluarga yang terdiri dari respon fisik meliputi kelelahan, keluhan tubuh dan gangguan tidur; respon psikologis meliputi cemas, tegang, takut dan sedih; respon sosial meliputi komunikasi berkurang dan pengalaman baru.
\end{abstract}

Kata Kunci : Hospitalisasi, keluarga, pasien kritis 


\section{PENDAHULUAN}

Hospitalisasi merupakan suatu proses yang karena suatu alasan berencana atau darurat, dimana mengharuskan pasien untuk tinggal di Rumah Sakit, menjalani terapi dan perawatan sampai pemulangannya kembali ke rumah. Selama proses tersebut, pasien dan keluarga dapat mengalami berbagai kejadian yang menurut beberapa penelitian ditunjukkan dengan pengalaman yang sangat traumatik dan penuh dengan stres. Perawatan pasien di Rumah Sakit tidak hanya menimbulkan masalah bagi pasien, tetapi juga bagi keluarga. Banyak penelitian membuktikan bahwa perawatan pasien di rumah sakit menimbulkan stres pada keluarga (Supartini, 2004).

Keluarga adalah unit terkecil dari masyarakat yang terdiri atas kepala keluarga dan beberapa orang yang terkumpul dan tinggal di suatu tempat di bawah suatu atap dalam keadaan saling ketergantungan. Keluarga adalah unit terkecil dalam masyarakat merupakan klien keperawatan atau si penerima asuhan keperawatan. Keluarga berperan dalam hospitalisasi anggota keluarga yang sakit (Jhonson, 2010).

Hampir semua keluarga berespon terhadap penyakit dan hospitalisasi pasien dengan reaksi yang luar biasa konsisten. Pada awalnya keluarga bereaksi dengan tidak percaya, terutama jika penyakit tersebut muncul tiba-tiba dan serius. Setelah realisasi penyakit keluarga bereaksi dengan marah. Takut, cemas dan frustasi merupakan perasaan yang banyak diungkapkan oleh keluarga (Wong, 2009).

Pasien kritis adalah pasien dengan penyakit atau kondisi yang mengancam keselamatan jiwa pasien tersebut. Keperawatan kritikal adalah suatu bidang yang memerlukan perawatan pasien yang berkualitas tinggi dan komprenhensif. Untuk pasien yang kritis, waktu adalah vital. Proses keperawatan memberikan suatu pendekatan yang sistematis, dimana perawat keperawatan kritis dapat mengevaluasi masalah pasien dengan cepat (Laura, 2004).

Klasifikasi pasien yang membutuhkan perawatan kritis harus berfokus pada tingkat perawatan yang dibutuhkan oleh masing-masing individu, dimanapun mereka berada. Klasifikasi ini mengalami pergeseran dari pengelompokan pasien berdasarkan geografis pasien, misalnya Intensive Care Unit (ICU) dan High Depencency Unit (HDU), menuju suatu sistem klasifikasi yang menggambarkan adanya jenjang menaik tingkatan perawatan untuk setiap pasien, tidak tergantung pada lokasi mereka di dalam Rumah Sakit (Jevon, 2009).

Data yang diperoleh Rekam Medik RS Dr. Bratanata Jambi diketahui jumlah pasien yang dirawat di ruang ICU tahun 2015 sebanyak 395 pasien, tahun 2016 sebanyak 411 pasien, dan tahun 2017 sebanyak 621 pasien. Setiap tahun terjadi peningkatan jumlah pasien di ruang ICU tersebut. Berdasarkan data-data yang didapat diatas, maka peneliti tertarik untuk mengetahui dan menggali pengalaman keluarga menghadapi hopitalisasi pasien kritis.

Survey awal pada tanggal 22 November 2017 terhadap 2 orang keluarga pasien kritis dengan menggunakan metode wawancara di RS Dr. Bratanata Jambi, keluarga mengatakan sedih, kasihan dan prihatin melihat keadaan anggota keluarganya yang kritis. Hasil wawancara terhadap 2 orang partisipan adalah sebagai berikut :

Partisipan 1: “ saya was-was mbak, bingung tidak tau harus bagaimana, takut apakah suami saya bisa sembuh atau tidak, saya sedih mbak, kasihan, perihatin, saya berdoa dan bersabar semoga suami saya cepat 
sembuh mbak, saya merasa pegal-pegal, masuk angin, pilek".

Partisipan 2 : “ saya panik, bingung, bleng mbak, soalnya bapak baru pertama kali dirawat di rumah sakit dan langsung di rawat di ICU, saya kuatir dan kasihan mbak, saya merasa kurang enak badan, sempat masuk angin juga mbak, kemaren sempat kerokan".

Peristiwa atau fenomena diatas, dapat memicu peneliti untuk tertarik melakukan penelitian tentang pengalaman keluarga menghadapi hospitalisasi pasien kritis yang dirawat di ruang ICU RS Dr. Bratanata Jambi.

\section{METODE PENELITIAN}

Jenis penelitian ini adalah penelitian kualitatif, yaitu metode penelitian yang digunakan untuk meneliti pada kondisi obyek yang alamiah, dimana peneliti adalah sebagai instrumen kunci, teknik pengumpulan data dilakukan secara trianggulasi (Sugiyono, 2016). Peneliti memilih jenis penelitian kualitatif karena ingin memperoleh jawaban mengenai bagaimana pengalaman keluarga pasien dalam menunggu pasien kritis yang dirawa di ruang ICU.

Penelitian ini menggunakan pendekatan fenomenologis, yaitu fokus pada berbagai pengalaman individu yang bersifat universal yang dialami oleh seorang individu terhadap suatu fenomena yang dialaminya dalam kehidupan sehari-hari. Peneliti menggunakan pendekatan ini karena ingin mendapatkan data dengan cara memahami bentuk pengalaman hidup responden sebagai individu yang mengalami keadaan sebenarnya yaitu tentang menunggu pasien kritis yang di rawat di ruang ICU. Analisis data pada penelitian ini menggunakan model Colaizzi (1978, dalam Streubert \& Carpenter, 2003).

\section{HASIL DAN PEMBAHASAN}

\begin{tabular}{cccc}
\multicolumn{4}{c}{ Distribusi Karakteristik Partisipan } \\
\hline No. & Inisial & Usia & $\begin{array}{c}\text { Status dg } \\
\text { pasien }\end{array}$ \\
\hline 1. & Ny. M & $41 \mathrm{Th}$ & Ibu \\
2. & Tn. S & $50 \mathrm{Th}$ & Suami \\
3. & Ny. S & $32 \mathrm{Th}$ & Anak \\
4. & Nn. A & $27 \mathrm{Th}$ & Anak \\
5. & Ny. L & $42 \mathrm{Th}$ & Istri \\
\hline
\end{tabular}

Partisipan yang diwawancarai merupakan 1 Laki-laki dan 4 Perempuan, berusia antara 27-50 Tahun. Jumlah partisipan dalam penelitian ini diambil sebanyak 5 partisipan, karena peneliti menyesuaikan tercapainya saturasi data dari masing-masing data yang telah diperoleh dari keseluruhan partisipan. Peneliti berusaha semaksimal mungkin mendapat informasi dari 5 partisipan tersebut sehingga diperoleh data yang sesuai dengan tujuan penelitian

Hasil wawancara kepada 5 partisipan menunjukkan ada hubungan dengan tema. Tema yang dibahas dalam analisa data meliputi :

Respon hospitalisasi pasien kritis di ruang ICU bagi keluarga memiliki tiga kategori. Kategori tersebut dihasilkan berdasarkan penggolongan kata kunci dan sub kategoridari hasil wawancara kepada partisipan. Kategori yang didapatkan oleh peneliti antara lain

a. Respon Fisik

Pasien kritis yang mengalami hospitalisasi akan menimbulkan respon fisik terhadap keluarganya yang telah menemaninya. Berdasarkan data dari hasil wawancara mendalam menunjukkan lima partisipan mengalami kelelahan, keluhan tubuh dan gangguan tidur. Dua dari lima partisipan yang mengalami kelelahan, saturasi dengan dokter dan perawat, Empat dari lima partisipan yang menyatakan bahwa respon fisik dalam menghadapi pasien kritis yaitu keluhan 
tubuh. Empat dari lima partisipan yang menyatakan bahwa respon fisik dalam menghadapi pasien kritis yaitu gangguan tidur.

\section{b. Respon Psikologi}

Pasien kritis yang mengalami hospitalisasi dapat menimbulkan respon kepada keluarga, sehingga keluarga mengalami emosi. Berdasarkan data hasil wawancara mendalam menunjukkan bahwa empat dari lima partisipan mengalami cemas, empat dari lima partisipan mengalami tegang, tiga dari lima partisipan mengalami sedih, dan tiga dari lima partisipan mengalami takut.

\section{c. Respon Sosial}

Keluarga yang sedang mengalami hospitalisasi pasien kritis yang dirawat di ruang ICU juga mengalami respon sosial. Sosialisasi keluarga terhadap tetangga atau saudara berkurang karena keluarga sibuk, kelelahan serta lebih mementingkan saudaranya yang dirawat di ruang ICU. Hasil wawancara mendalam menunjukkan empat partisipan menjadi komunikasi berkurang dan lima partisipan mempunyai pengalaman baru.

\section{Hasil Penelitian Pengalaman} keluarga menghadapi hospitalisasi pasien kritis di ruang ICU, respon fisik yang meliputi kelelahan, keluhan tubuh dan gangguan tidur; respon psikologis meliputi cemas, tegang, takut dan sedih; respon sosial meliputi komunikasi berkurang dan pengalaman baru.

Pasien yang menderita sakit kritis akan mengalami hospitalisasi. Pengalaman Hospitalisasi dapat mengganggu psikologi dan psikososial keluarga terlebih bila keluarga tidak dapat beradaptasi dengan lingkungan barunya di Rumah Sakit. Hospitalisasi menyebabkan keluarga akan memainkan perannya terutama terhadap anggota keluarga yang tergantung, seperti anak yang sakit akan tergantung pada orang yang melindunginya (Supartini, 2004).

\section{a. Respon Fisik}

Hasil penelitian yang dilakukan oleh peneliti bahwa respon fisik yang timbul selama menunggu pasien kritis yang dirawat di ruang ICU, yaitu timbul kelelahan, keluhan tubuh dan gangguan tidur.

Kecukupan waktu tidur seseorang sebenarnya tidak hanya diukur dari lama waktu tidur, tetapi juga kualitas tidur itu sendiri. Selain itu, sebenarnya tidur tidak hanya mengistirahatkan tubuh, tetapi juga mengistirahatkan otak, khususnya serebral korterk, yakni bagian otak terpenting atau fungsi mental tertinggi, yang digunakan untuk mengingat, memvisualkan resta membayangkan, menilai dan memberikan alasan tertentu (Subandi, 2008).

Hasil penelitian ditemukan bahwa gangguan tidur yang dialami partisipan disebabkan karena kondisi ruang tunggu yang dipakai secara bersama-sama oleh seluruh keluarga penunggu pasien kritis di ruang ICU, seperti adanya suara keluarga yang keluar-masuk ruang tunggu, pikiran yang tidak menentu terhadap anggota keluarganya yang sakit serta lingkungan udara yang dingin saat malam hari sehingga menyebabkan kualitas tidurnya keluarga terganggu.

Kelelahan adalah suatu kondisi yang memiliki tanda berkurangnya kapasitas yang dimiliki seseorang untuk bekerja dan mengurangi efisiensi prestasi, dan biasanya hal ini disertai dengan perasaan letih dan lemah (Arnot, 2009).

Kelelahan dalam hasil penelitian ini dikarenakan keluarga merasa capek menunggu anggota keluarganya di ruang ICU. Rasa capek keluarga disebabkan karena pola tidur yang tidak teratur dan keluarga yang harus hilir mudir memantau kondisi keluarga yan dirawat. 
Keluhan tubuh pada keluarga yang menunggu pasien di ICU disebabkan karena keluarga tidak sempat mengontrol / mengecek kesehatannya. Keluarga lebih memikirkan kesehatan anggota keluarganya yang dirawat, tanpa memikirkan kesehatannya sendiri, padahal kondisi kesehatan sangat penting dalam menunggu pasien di ICU.

\section{b. Respon Psikologi}

Hasil penelitian yang dilakukan bahwa respon psikologi yang timbul selama menunggu pasien kritis yang dirawat di ruang ICU, yaitu berupa cemas, tegang, sedih dan takut. Kebanyakan keluarga merasa cemas saat anggota keluarganya dirawat di ruang ICU dan ketika keluarga mendapat panggilan dari petugas kesehatan terkait anggota keluarga yang dirawat di ruang ICU.

Kecemasan adalah respon individu terhadap suatu keadaan yang tidak menyenangkan dan dialami oleh seluruh makhluk hidup. Stuart dan Laraia mendefenisikan ansietas sebagai pengalaman emosi dan subyektif yang bersifat individual. Ansietas adalah respon emosi tanpa subyek yang spesifik sehingga klien merasakan suatu perasaan was-was seakan sesuatu yang buruk akan terjadi dan biasanya disertai gejala-gejala otonomik yang berlangsung beberapa hari, bulan bahkan tahun (Sumiati, 2009).

Rasa takut muncul pada keluarga terutama akibat takut kehilangan pasien pada kondisi sakit yang terminal. Rasa takut yang dialami keluarga, yaitu sering bertanya atau bertanya hal yang berulang-ulang pada orang yang berbeda. (Supartini, 2004). Rasa takut yang dialami keluarga saat menunggu pasien kritis di ruang ICU, yaitu keluarga takut akan kehilangan anggota keluarganya, keluarga takut bahwa anggota keluarganya dan kecilnya kemungkinan untuk sembuh.
Rasa sedih yang dialami keluarga muncul terutama pada saat pasien dalam kondisi terminal dan keluarga mengetahui bahwa tidak ada lagi harapan bagi pasien untuk sembuh. Hasil penelitian menunjukkan bahwa keluarga mengalami sedih ketika anggota keluarganya harus dirawat di ruang ICU.

\section{c. Respon sosial}

Hasil penelitian yang dilakukan oleh peneliti bahwa respon sosial ketika keluarga menunggu pasien kritis di ruang ICU, yaitu komunikasi berkurang dan adanya pengalaman baru. Keluarga mengalami komunikasi berkurang di lingkungan tempat tinggalnya karena keluarga sibuk dalam menemani salah satu anggota keluarganya yang dirawat di ruang ICU. Komunikasi adalah penyampaian seseorang kepada orang lain, dengan menyertakan kode atau lambang penyampaiannya itu sendiri melalui suatu proses (Kariyoso, 2005).

Faktor yang mempengaruhi komunikasi keluarga dalam menunggu pasien kritis di ruang ICU, yaitu persepsi keluarga dengan perawat. Komunikasi juga dipengaruhi oleh sosial. Pengaruh komunikasi yang lain adalah saluran atau alat tubuh dari komunikator terutama dalam komunikasi lisan (Kariyoso, 2005).

Hasil penelitian ini juga mendapat hikmahnya yaitu keluarga mengerti keadaan dan kondisi ruang ICU, keluarga mendapat teman baru untuk saling bercerita tentang kondisi keluarganya sehingga keluarga mendapat pengalaman baru.

\section{SIMPULAN}

Penelitian ini dilakukan oleh peneliti terhadap 5 orang partisipan, dari hasil penelitian dengan wawancara mendalam yang dilakukan oleh peneliti, bahwa pengalaman keluarga menghadapi hospitalisasi pasien kritis di 
ruang ICU dapat diambil kesimpulan antara lain, Respon keluarga menghadapi hospitalisasi pasien kritis di ruang ICU antara lain menimbulkan respon fisik yang meliputi kelelahan, keluhan tubuh dan gangguan tidur; respon psikologis meliputi cemas, tegang, takut dan sedih; respon sosial meliputi komunikasi berkurang dan pengalaman baru.

\section{SARAN}

1. Bagi Institusi Pendidikan Keperawatan. Pasien Kritis itu tidak hanya berfokus pada pasien, tapi juga keluarga pasien yang dirawat, bagi intitusi pendidikan untuk lebih memperdalam ilmu keperawatan khususnya keperawatan pasien kritis.

2. Bagi Pihak Rumah Sakit. Petugas kesehatan atau non kesehatan yang khususnya berada di ruang ICU sebaiknya ikut memperhatikan kondisi keluarga pasien, agar keluarga merasa nyaman dan tidak bingung. Petugas kesehatan agar memberikan informasi terkait keadaan pasien dan peraturan menunggu pasien di ruang ICU yang sejelas-jelasnya agar keluarga paham dan tidak merasa khawatir akan keadaan anggota keluarganya.

3. Bagi Peneliti Selanjutnya. Untuk dapat melakukan penelitian secara kuantitatif dengan cara membandingkan atau mengetahui lebih dalam hubungan variabelvariabel yang tergambar di tema dalam penelitian ini.

4. Bagi Keluarga Pasien. Agar dapat meningkatkan pengetahuan mereka tentang penyakit-penyakit kritis sehingga mengurangi tingkat kecemasan, kekhawatiran serta rasa panik keluarga terhadap keluarga yang sedang dirawat di ruang ICU.

\section{DAFTAR PUSTAKA}

1-161. Wong DL. Buku Ajar : Keperawatan Pediatrik. Jakarta: EGC; 2009.

2. Talbot L. Pengkajian Keperawatan Kritis. Jakarta: EGC; 2004.

3. Suyanto. Metodologi Dan Aplikasi Penelitian Keperawatan. Yogyakarta: Nuha Medika; 2011.

4. Sugiyono. Memahami Penelitian Kualitatif. Bandung: Alfabeth; 2016.

5. Sabarguna BS. Manajemen Kinerja Pelayanan Rumah Sakit Dan Manajemen Resiko Klinis Untuk Rumah Sakit. Jakarta: Sagung seto; 2009.

6. Rasmun. Keperawatan Kesehatan Mental Psikiatri Terintegrasi Dengan Keluarga. Jakarta: Sagung seto; 2009.

7. Nursalam. Metodologi Penelitian. Jakarta: Salemba Medika; 2005.

8. Ningsih SS. Pengalaman keluarga menghadapi Hospitalisasi pasien kritis di Ruang ICU RSUP Dr. Kariadi Semarang. Skripsi Univ Diponegoro Semarang. 2017.

9. Lumenta B. Peran Dan Perilaku. Yogyakarta: Kanisius; 1998.

10. Kariyoso. Pengantar Komunikasi Bagi Siswa Perawat. Jakarta: EGC; 2005.

11. Jhonson. Keperawatan Keluarga. Yogyakarta: Nuha Medika; 2010.

12. Jevon P. Pemantauan Pasien Kritis. Jakarta: Erlangga; 2009.

13. Hudak CM. Keperawatan Kritis. Jakarta: EGC; 1997.

14. Herawati M. Gambaran Tingkat Kecemasan Keluarga terhadap Pasien Kritis di Ruang ICU RS Dr. Bratanata Jambi tahun 2013. karya tulis Ilm Akad Keperawatan Garuda Putih 
Jambi. 2013.

15. Haliman A. Cerdas Memilih

Rumah Sakit. Yogyakarta: Rapha Publishing; 2012.

16. Alimul A. Metode Penelitian

Keperawatan Dan Teknik

Analisis Data. Jakarta: Salemba

Medika; 2011. 